\title{
Prioritising teaching modalities by extending TOPSIS to single- valued neutrosophic environment
}

\author{
Neeraj Chopra $^{1}$ (D) Rajiv Sindwani ${ }^{1} \cdot$ Manisha Goel $^{1}$
}

Received: 9 March 2021 /Revised: 5 May 2021/Accepted: 31 August 2021/Published online: 8 September 2021

(C) The Society for Reliability Engineering, Quality and Operations Management (SREQOM), India and The Division of Operation and Maintenance, Lulea University of Technology, Sweden 2021

\begin{abstract}
An effective teaching modality not only improves the efficiency of the teaching process but also promotes active learning. Teaching modalities are continuously evolving due to advancement in technology. There is a range of contradictory reports available in the extant literature regarding the effectiveness of different teaching modalities. This work assesses and prioritises four teaching modalities namely face-to-face teaching, pure online teaching, blended teaching and flipped classroom teaching. Assessment is made based on 8 criteria identified from the literature in consultation with the experts. Analysis revealed that the flipped classroom and blended teaching approaches are the most effective teaching modalities. Examination of the literature indicates that to date no study evaluated all the four aforementioned teaching modalities in a single study. The study is the first attempt to assesses 4 teaching modalities based on 8 eight common criteria by extending TOPSIS to a single-valued neutrosophic environment. Current work provides valuable insights to various stakeholders including academicians, policymakers and practitioners, who are interested in giving a rich learning experience to learners.
\end{abstract}

Neeraj Chopra

neeraj7375@gmail.com

Rajiv Sindwani

rajiv_sindwani@yahoo.co.in

Manisha Goel

singla_manisha@rediffmail.com

1 J.C. Bose University of Science and Technology, YMCA, Faridabad 121006, India
Keywords Teaching modality · Face-to-face teaching Pure online teaching $\cdot$ Blended teaching - Flipped classroom teaching $\cdot$ TOPSIS

\section{Introduction}

Nowadays, teachers are using innovative teaching technologies in their sessions for making learners autodidactic with high order thinking skills (Namaziandost and Çakmak 2020). Consequently, a transition has been seen in teaching modalities from traditional, face-to-face classroom teaching modality to a variety of contemporary technology-enabled teaching modalities (Redmond 2011). Contemporary technology-enabled teaching modalities include pure online teaching, blended teaching, and flipped classroom teaching. Cheng et al. (2019) discussed that transition in teaching modalities has been valued because it converted the teaching process from instructor-centred to learnercentred. Teaching modalities can be described as the activities (e.g., auditory, visual and tactile) used by teachers in their sessions for improving students' engagement. Teachers believe that an effective teaching modality not only improves the teaching efficiency of the teaching process but also promotes active learning. Every teaching modality has its advantages and disadvantages. For instance, Wright (2017) asserted that students feel highly motivated in traditional classroom settings due to the physical presence of teachers and peers. Interestingly, both teachers and students valued classroom discussions for a deeper understanding of learning content. Wei et al. (2020) opined that due to the rich learning experience gained by learners in contemporary teaching modalities, their performance in the course improves. Consequently, 
contemporary teaching modalities are becoming need nowadays and teachers must incorporate them for increased academic performance. Many studies discussed the benefits of the traditional and contemporary teaching modalities as accessibility, flexibility, convenience, costeffectiveness, and active learning (Cheng et al. 2019; Strelan et al. 2020; Namaziandost and Çakmak 2020; Mahmood 2021). Despite benefits, some issues exist in available teaching modalities whether it is traditional faceto-face classroom teacher or contemporary one. For example, Tang et al. (2017) criticised face-to-face classroom teaching modality for the teacher-centric approach where learners get limited autonomy during the teaching session. Hence, they absorb the information given in the class passively resulting in poor teaching effects ( $\mathrm{Li}$ and Shan 2020). Dhawan (2020) argued that pure online teaching makes learner socially inactive resulting in isolation. Researcher also added that limited involvement and technical issues encountered during learning leads to learners' frustration. The various other shortcomings observed in this mode include a requirement of self-regulation and self-motivation (Grimes 2002; Browne 2005). Moreover, Ubell (2017) noticed a lack of rigorous teaching pedagogy in technology-enabled teaching modalities, which raises specific concerns over its effectiveness. McKenna et al. (2020) asserted that the ideal blend of offline and online teaching is very difficult to achieve. Hence, its practical implementation is a complex task resulting in low-grade learning outcomes. Singh et al. (2018) investigated flipped classroom model and found that it suffers from problems such as learning tradition, limited spontaneous query handling, and requirement of self-regulated learning skills of learners. Moreover, Strelan et al. (2020) found that the performance of students in a flipped classroom is not uniform across all discipline of studies. It was noticed that the aforementioned studies investigated specific teaching modality and outlined their benefits and shortcomings. However, some studies compared teaching modalities. For example, Roach and Lemasters (2006) reported no significant difference between face-to-face and pure online teaching modalities. Woltering et al. (2009) compared traditional learning with blended learning and claimed that problem-based learning is better in a blended mode of teaching. But on the other hand, some studies had observed no statistically significant difference between the two modes in terms of achievement of learning outcomes (Hsu and Hsieh 2011). While comparing traditional mode with flipped classroom model particularly for a mathematics course, Sahin et al. (2015) noticed that students achieved higher grades in the flipped classroom. But, Ryan and Reid (2015) informed that both the models did not show statistically significant difference in the performance of students. In light of the aforementioned shreds of evidence, it can be said that findings regarding teaching modalities were found to be inconclusive. Hence, it is difficult to conclude which teaching is superior to others. Morevover, it was observed that most of the studies compared, maximum of three pedagogical approaches (Tang et al. 2017; Yen et al. 2018; Pei et al. 2019). As per the authors' knowledge, to date, no study evaluated all the four aforementioned teaching modalities in a single study. To evaluate them, the authors identified some common criteria from the extant literature. Based on the criteria, the multicriteria decision making (MCDM) technique is applied to prioritise the aforementioned teaching modalities.

The current work proposes the following objectives to give direction to the study. The objectives are:

1. To identify the common criteria from the learners' perspective for assessment of teaching modalities

2. To prioritise the teaching modalities using singlevalued neutrosophic extended TOPSIS

The remaining paper is organized as follows. The following section describes four different types of teaching modalities. The next section talks about the methodology used in research for identifying common criteria and prioritising teaching modalities. This is followed by the results and discussion section. Afterward, contributions and suggestions, conclusion, and limitations and future research scope have been discussed.

\section{Related work}

This section discusses the four different types of teaching modalities by highlighting their key features. The four teaching modalities are face-to-face classroom teaching, pure online teaching, blended teaching, and flipped classroom teaching (refer to Fig. 1).

Tang et al. (2017) described face-to-face classroom teaching as the well-established instructional medium where students attend classes in a brick-and-mortar environment. Here, the teaching style is predominantly teachercentric but extremely dynamic. The instructor discusses the topic in classroom in presence of students. For centuries, it has been a popular mode of teaching and learning. Cazden (1988) noticed that physical classroom interaction

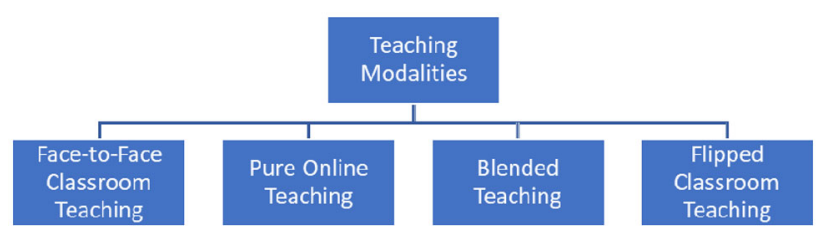

Fig. 1 Four different types of teaching modalities. Source: Developed by authors 
combines the cognitive and social aspects of the classroom which stimulates learners' thinking capabilities. Furthermore, the immediate response to the queries develops organic bonding between the teacher and the student. The physical presence of the instructor makes the learner more disciplined. As discussed above, the learner feels motivated in presence of teachers and peers, and motivation plays an instrumental role for the realisation of learning goals (Buddhapriya and Bhatt 2018). Westbury (1973) observed that the intellectual climate of the classroom gets enriched when the instructor discusses interesting stories in the class. It permits faculty to adjust the lecture pace as per need. Sometimes, faculty gives additional knowledge based on the interest of students for effective engagement. Kalpokaite and Radivojevic (2020) found that instructors preferred face-to-face teaching due to the emotional energy generated in the class due to healthy interaction. It is often called 'chalk-and-talk, 'frontal teaching' or 'conventional teaching'.

Pure online teaching modality is popularly called virtual learning mode or e-learning mode. Nguyen (2015) described pure online teaching modality as the technology-mediated flexible mode of learning where the learner can learn without geographical and temporal barriers. Most importantly, Bailey et al. (2018) informed that online teaching modality permit students to register in those courses which are unavailable to them due to non-availability of seats or scheduling constraints. Notably, higher education institutes adopted online teaching as the principal instructional modality due to the covid-19 outbreak (Zhou 2020). The various other benefits are accessibility, ease of use, freedom of navigation, high-quality images, review of lectures based on annotation and recording of lectures (Moazami et al. 2014; Zhou 2020). However, the course completion rate of the online course was found to be lower (Murphy and Stewart 2017). In particular, self-regulation is the most desirable characteristic for learners of this mode (Broadbent 2017). This can be developed by employing various types of self-management practices such as spiritual guidance and yoga (Wheeler et al. 2020).

Blended learning is described by Huang et al. (2021) as merging two teaching modalities i.e. face-to-face instruction and technology-mediated instruction to capitalize on the benefits of both. It is often referred to as 'hybrid learning' (Means et al. 2013). The mode delivers a major portion of the course content online with some face-to-face contact sessions to enhance the value of traditional mode through technology. Various multimedia tools are used for value enhancement. Furthermore, blended teaching modality nurtures independent learning among students, particularly, undergraduate students (Onah et al. 2020). Chu and Mok (2016) classified the mode into two main categories, synchronous and asynchronous blended mode.
Nevertheless, the blended synchronous mode gains an edge over asynchronous mode for a variety of reasons including active learning, high flexibility, increased learner satisfaction and inclusive and equitable learner experience ( $\mathrm{Li}$ et al. 2020).

The flipped classroom model is that educational setting where learner receive study material like instructional videos, PowerPoint handouts, and conceptual notes in advance, study them before attending lecture and applies the knowledge gained from the material by carrying out hands-on-session and/or problem-solving assignments in presence of instructors and peers (Namaziandost and Çakmak 2020). Moreover, according to Gopalan et al. (2018) in presence of the social environment of teachers and peers, students exhibit various level of motivation leading to improved academic performance. Studies noticed that enablers for knowledge creation and sharing are social interaction, communication, and mentoring (Sujatha and Krishnaveni 2020). It can be concluded that flipped classroom model supports knowledge creation and sharing because all aforementioned enablers are found in it. Nevertheless, the mode gives various benefits such as development of positive attitude in learner for studies, reduction of cognitive burden on the learner, and active, constructive and interactive learner engagement (Tomas et al. 2019; Van Alten et al. 2019). It is commonly called an 'inverted classroom'.

\section{Research methodology}

Based on the proposed objectives, a two phase research process is followed for evaluating the aforementioned teaching modalities. The first phase is related to identification of common criteria from the learners' perspective required for the assessment of teaching modalities. The second phase deals with implementation of single-valued neutrosophic extended TOPSIS method (Technique for Order Preference by Similarity to Ideal Solution) for prioritisation of teaching modalities on the basis of common criteria.

\subsection{Threats to validity}

To achieve the objectives of the research, best practices are followed at each stage of the research process. This will help in dealing with threats to validity that exist at each stage of the research process and make research design robust. The researchers adopted PRISMA guidelines for systematic review so that all the relevant studies are selected. Moreover, it is ensured that technique for evaluation of teaching modalities is applied in the appropriate 
manner. These measures were taken to improve the validity of the research.

\subsection{PRISMA framework}

To find out criteria for evaluating teaching modalities, PRISMA (Preferred Reporting Items for Systematic Reviews and Meta-Analyses) guidelines of Moher et al. (2009) were followed. Liberati et al. (2009) highlighted that the ultimate objective of PRISMA is to report literature review in a clear and transparent manner. Based on the guidelines, a review protocol was developed. The protocol covered search strategy, criteria for excluding articles and evaluation of quality.

\subsubsection{Search strategy}

Authors consulted Google Scholar for the systematic literature review. Various combinations of keywords were used to extract pertinent articles from Google Scholar. Articles were screened based on exclusion criteria presented in Table 1. Search resulted in total of 257 articles. Articles that come under exclusion criteria were removed. In order to extract relevant articles, author conducted abstracts review. After abstract review, authors selected 62 articles for full text review.

\subsubsection{Evaluation of quality}

The criterion mentioned in Table 2 was adapted from Nguyen-Duc et al. (2015). Every criterion had four possible scores: entirely fulfilled (3), sufficiently fulfilled (2), little fulfilled (1) and completely unfulfilled (0). After imposing quality assessment criterion, studies were arranged on the basis of their scores provided by the authors. Authors' shortlisted 46 studies having average quality score greater than 1.5. Selected articles were analyzed in depth by the authors.

\subsection{Methodology for identification of common criteria}

The shortlisted articles were analysed in depth by the authors and various criteria that can be used for evaluation

Table 1 Exclusion criteria

\begin{tabular}{ll}
\hline Code & Exclusion criteria \\
\hline EX-C1 & Articles in language other than English \\
EX-C2 & Articles where teaching modalities is not the major theme \\
EX-C3 & Grey Literature \\
\hline
\end{tabular}

Table 2 Quality assessment criteria

\begin{tabular}{ll}
\hline Code & Criteria \\
\hline $\mathrm{C} 1$ & Well defined problem statement \\
$\mathrm{C} 2$ & Robust Research design \\
$\mathrm{C} 3$ & Data analysis is unambiguous \\
$\mathrm{C} 4$ & Findings are clearly reported \\
\hline
\end{tabular}

of teaching modalities were identified from them. The identified criteria were discussed in detail with the three experts. Experts were coded as E1, E2, and E3. Out of three, two experts were from academia, one is working as a professor in a degree college with more than 26 years of experience and the other is working as senior faculty in a school with more than 21 years of experience. The third expert is a manager in an EdTech company with an experience of 16 years.

\subsection{Algorithm for extended TOPSIS using SVN sets}

Multi-criteria decision-making problems use information from a variety of sources. There are chances that some part of this information may be imperfect. There are various forms of the imperfection of information such as uncertainty, imprecision, vagueness and incompleteness. Literature proposed various theories like fuzzy set logic and neutrosophic sets for handling such imperfections of information. Fuzzy set logic was particularly used for handling imperfection such as imprecision and vagueness (Smets 1999). In contrast, neutrosophic sets are observed as a robust tool for dealing with all types of imperfections (Pramanik and Mondal 2015). The literature discussed various MCDM techniques for prioritisation of alternatives like AHP and Fuzzy AHP. But there exist some studies which criticised AHP and Fuzzy AHP on many grounds (Moayeri et al. 2015; Zhu 2014). For instance, the traditional AHP method is problematic in that it uses an exact value to express the decision-makers opinion in a comparison of alternatives. Moreover, the judgement scale is unbalanced and is incapable of dealing with inherent uncertainty and imprecision in the pairwise comparison process. AHP permits a certain degree of inconsistency in the pairwise comparison process. As far as Fuzzy AHP is concerned, it violates the fundamental logic fuzzy set theory. There is a lack of a proper definition form of fuzzy numbers indicating that fuzzy numbers are arbitrary. Nevertheless, no membership grade is used here that makes the calculation process distinct from the calculation characteristics fuzzy set theory. There is no one-to-one correspondence between fuzzy numbers and their alpha cut. 
Additionally, there is no generally accepted method to rank fuzzy numbers as well as for checking the consisting index.

Hwang and Yoon (1981) proposed TOPSIS, a popular MCDM method for solving real-world complex problems. To deal with vagueness, uncertainties and ambiguities in real-world issues, studies extended TOPSIS under a fuzzy and intuitionistic environment for effective handling of MCDM problems (Chen 2000; Boran et al. 2009). Smarandache (1998) proposed an enhancement to IFS (intuitionistic fuzzy sets) theory called neutrosophic set theory which loosely refers to neutral knowledge. As neutrosophic sets are observed as a robust tool for dealing with all types of imperfections, the current study adopted an algorithm used for extending TOPSIS using SVNN (Single-valued neutrosophic numbers) on the basis of study conducted by Biswas et al. (2019). The application proved useful in various studies like logistic centre location selection, typhoon disaster management (Pramanik et al. 2016; Tan and Zhang 2021). Smarandache (1999) discussed SVN sets as a special provision of NS (neutrosophic set) composed of three independent components namely, truth, falsity, and indeterminacy. The set permits quantification of indeterminacy (Das et al. 2020). Wang et al. (2010) defined Q as NS of SVNs, containing three membership functions as truth membership function $T_{Q}(x)$, indeterminacy membership function $I_{Q}(x)$, and falsity membership function $F_{Q}(x)$. Here, x denotes generic element belongs to space of objects $\mathrm{X}$. Hence, SVN Q is denoted as $\left\{\left\langle x, T_{Q}(x), I_{Q}(x), F_{Q}(x)\right\rangle \mid x \in X\right\}$. The truth, indeterminacy and falsity values lie between 0 and 1 . For instance, $T_{Q}(x), I_{Q}(x), F_{Q}(x) \rightarrow[0,1]$. Thus, the sum of $T_{Q}(x), I_{Q}(x) \quad$ and $\quad F_{Q}(x) \quad 0 \leq \sup _{Q}(x)+\sup I_{Q}(x)+$ $\operatorname{supF}_{Q}(x) \leq 3$. The algorithm is described as follows (refer to Fig. 2).

1. Chosen experts were assessed based on the experience, knowledge and skills using Table 3 that shows linguistic terms along with their corresponding SVNN. The weight of the kth expert is calculated based on Eq. (1).

$$
\omega_{K}=\frac{1-\sqrt{\left\{\left(1-T_{K}\right)^{2}+\left(I_{K}\right)^{2}+\left(F_{K}\right)^{2}\right\} / 3}}{\sum_{k=1}^{p}\left(1-\sqrt{\left.\left\{\left(1-T_{K}\right)^{2}+\left(I_{K}\right)^{2}+\left(F_{K}\right)^{2}\right\} / 3\right)}\right.}
$$

2. MCDM problem composed of $m$ alternatives and $n$ criteria. For instance, $A=\left\{a_{1}, a_{2}, a_{3}, \ldots \ldots, a_{m}\right\}$ be the set of $\mathrm{m}$ alternatives, $C=\left\{C_{1}, C_{2}, C_{3}, \ldots \ldots, C_{n}\right\}$ be set of well-defined criteria. Experts assessed alternatives individually, in linguistic terms mentioned in Table 4, corresponding to the identified criteria. These assessments are further expressed as a decision matrix (refer to Eq. 2). The linguistic terms are converted into the corresponding SVNN using Table 3.

$$
D=\left\langle d_{i j}\right\rangle_{m x n}=\left[\begin{array}{cccc}
d_{11} & d_{12} & \vdots & d_{1 n} \\
d_{21} & d_{22} & \vdots & d_{2 n} \\
\cdots & \ldots & \vdots & \ldots \\
d_{m 1} & d_{m 2} & \vdots & d_{m n}
\end{array}\right]
$$

3. Further, individual ratings are aggregated using SVWNA (single-valued neutrosophic weighted averaging) aggregation operator introduced by Ye (2014) (refer to Eq. 3), to generate aggregated single-valued neutrosophic decision matrix $D_{\text {agg }}$.

$$
\begin{gathered}
D_{A g g}=\left\langle d_{i j}\right\rangle_{m x n}=\left\langle 1-\prod_{k=1}^{p}\left(1-T_{i j}^{(p)}\right)^{\varphi_{k}}, \prod_{k=1}^{p}\left(I_{i j}^{(p)}\right)^{\varphi_{k}}\right. \\
\left.\prod_{k=1}^{p}\left(F_{i j}^{(p)}\right)^{\varphi_{k}}\right\rangle
\end{gathered}
$$

4. Additionally, experts assessed criteria taking into account their relative significance in a particular teaching modality. To obtain the aggregated assessment of various criteria Eq. (3) is utilised leading to a weight vector $W=\left\{W_{1}, W_{2}, W_{3}, \ldots, W_{n}\right\}$.

5. Construction of aggregated weighted neutrosophic decision matrix (AWDM) is done by multiplying matrix D and W using Eq. (4).

$D^{W}=D_{A g g} X W=\left\langle d_{i j}^{w_{j}}\right\rangle_{m x n}$

6. Compute the relative neutrosophic positive (RNPIS) and negative neutrosophic ideal (RNNIS) solutions for SVNNs. They are represented as $Q_{N}^{+}$and $Q_{N}^{-}$can be computed using Eq. (5) and (6) respectively.

$$
\begin{aligned}
& Q_{N}^{+}=\left[d_{1}^{w+}, d_{2}^{w+}, \ldots \ldots, d_{n}^{w+}\right] \\
& \text { whered }_{j}^{w+}\left\langle T_{j}^{w+}, I_{j}^{w+}, F_{j}^{w+}\right\rangle \text { forj }=1,2,3, \ldots, n \\
& Q_{N}^{-}=\left[d_{1}^{w-}, d_{2}^{w-}, \ldots \ldots, d_{n}^{w-}\right] \\
& \text { whered }_{j}^{w-}\left\langle T_{j}^{w-}, I_{j}^{w-}, F_{j}^{w-}\right\rangle \text { forj }=1,2,3, \ldots, n \\
& T_{j}^{w+}=\left\{\left({ }_{i}^{\max }\left\{T_{i j}^{w j}\right\} \mid j \in J_{1}\right),\left({ }_{i}^{\min }\left\{T_{i j}^{w j}\right\} \mid j \in J_{2}\right)\right\} \\
& I_{j}^{w+}=\left\{\left({ }_{i}^{\min }\left\{I_{i j}^{w j}\right\} \mid j \in J_{1}\right),\left({ }_{i}^{\max }\left\{I_{i j}^{w j}\right\} \mid j \in J_{2}\right)\right\} \\
& F_{j}^{w+}=\left\{\left({ }_{i}^{\min }\left\{F_{i j}^{w j}\right\} \mid j \in J_{1}\right),\left({ }_{i}^{\max }\left\{F_{i j}^{w j}\right\} \mid j \in J_{2}\right)\right\}
\end{aligned}
$$




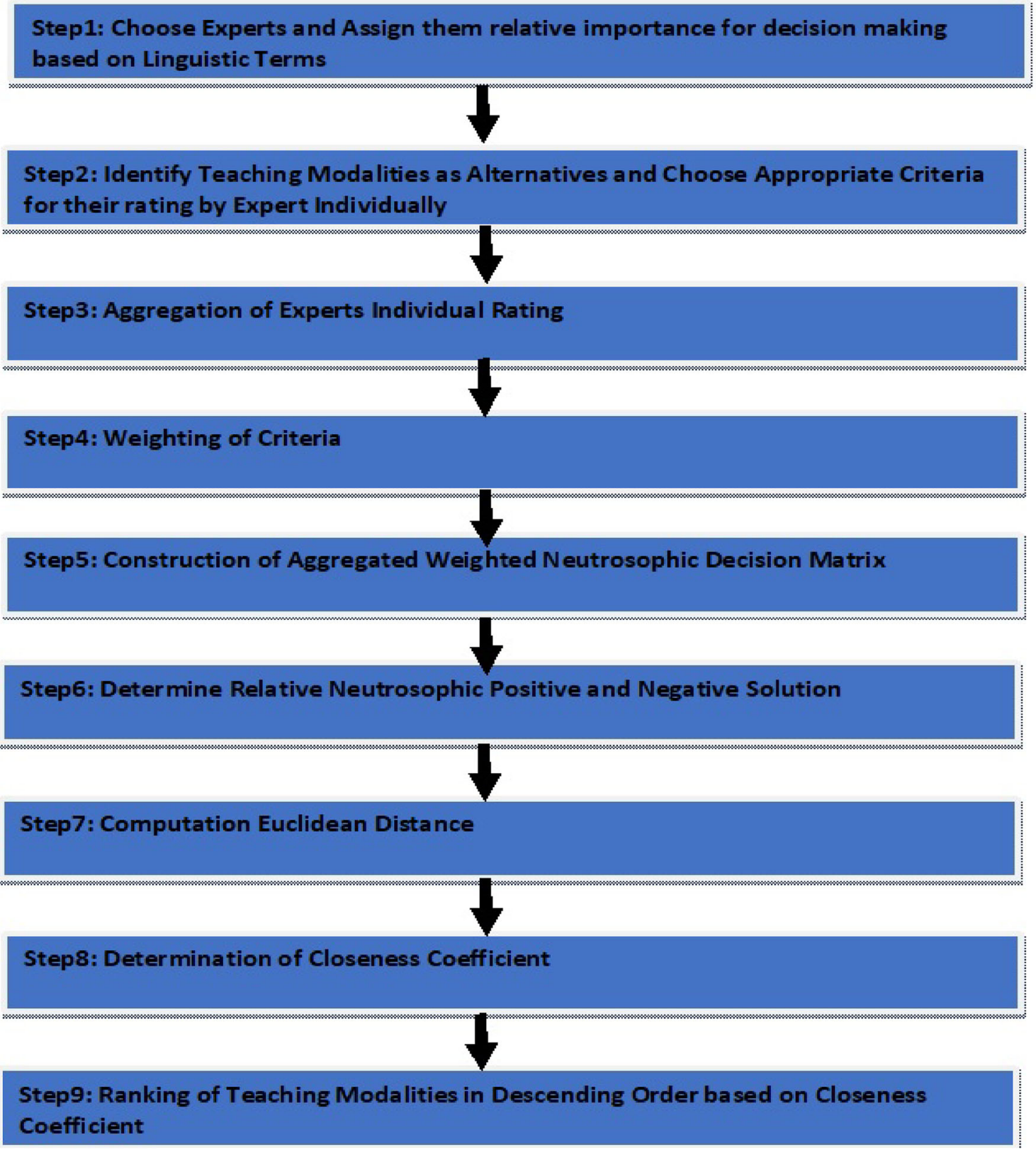

Fig. 2 Algorithm of SVN extension to TOPSIS. Source: Developed by authors

Table 3 Linguistic terms for assessment of criteria and experts. Adapted from Source Biswas et al. 2019

\begin{tabular}{ll}
\hline Linguistic Terms & SVNNs \\
\hline Most Important (MI) & $\langle 0.90,0.10,0.10\rangle$ \\
Important (I) & $\langle 0.80,0.20 .0 .15\rangle$ \\
Medium (M) & $\langle 0.50,0.40,0.45\rangle$ \\
Unimportant (UI) & $\langle 0.35,0.60,0.70\rangle$ \\
Most Unimportant (MUI) & $\langle 0.10,0.80,0.90\rangle$ \\
\hline
\end{tabular}

$$
\begin{aligned}
& T_{j}^{w-}=\left\{\left({ }_{i}^{\min }\left\{T_{i j}^{w j}\right\} \mid j \in J_{1}\right),\left({ }_{i}^{\max }\left\{T_{i j}^{w j}\right\} \mid j \in J_{2}\right)\right\} \\
& I_{j}^{w-}=\left\{\left({ }_{i}^{\max }\left\{I_{i j}^{w j}\right\} \mid j \in J_{1}\right),\left({ }_{i}^{\min }\left\{I_{i j}^{w j}\right\} \mid j \in J_{2}\right)\right\} \\
& F_{j}^{w-}=\left\{\left({ }_{i}{ }^{\max }\left\{F_{i j}^{w j}\right\} \mid j \in J_{1}\right),\left({ }_{i}^{\min }\left\{F_{i j}^{w j}\right\} \mid j \in J_{2}\right)\right\}
\end{aligned}
$$

Here, $J_{1}$ and $J_{2}$ refers to benefit type and cost type criteria. 
Table 4 Linguistic terms for assessment of alternatives. Adapted from Source Biswas et al. 2019

\begin{tabular}{ll}
\hline Linguistic Terms & SVNNs \\
\hline Extremely Significant (ES) & $\langle 1.00,0.00,0.00\rangle$ \\
Very Significant (VS) & $\langle 0.90,0.10,0.05\rangle$ \\
Significant (S) & $\langle 0.80,0.20,0.15\rangle$ \\
Moderately Significant (MS) & $\langle 0.65,0.35,0.30\rangle$ \\
Neutral & $\langle 0.50,0.50,0.45\rangle$ \\
Moderately Insignificant (MIS) & $\langle 0.35,0.65,0.60\rangle$ \\
Insignificant (IS) & $\langle 0.20,0.75,0.80\rangle$ \\
Very Insignificant (VI) & $\langle 0.10,0.85,0.90\rangle$ \\
Extremely Insignificant (EI) & $\langle 0.05,0.90,0.95\rangle$ \\
\hline
\end{tabular}

7. Compute Euclidean distance measure of every alternative from the RNPIS and RNNIS using (13) and (14) respectively. given to three experts (E1, E2 and E3) as mentioned in Table 3. Table 6 presents the decision power of experts in terms of linguistic ratings and their corresponding SVNNs. Further, Experts' weights were calculated using Eq. (1). The computed weights of E1, E2 and E3 are 0.420, 0.357 and 0.223 respectively. E1 got the highest weight among all the experts.

Experts gave linguistic assessments to the aforementioned teaching modalities concerning various criteria as mentioned in Table 4. Table 7 presents the linguistic assessment of teaching modalities.

Further, assessments are expressed in their corresponding SVNN resulting in an individual matrix. Thereafter Eq. (3) was applied on all individual matrices for aggregation of SVNNs. It yields aggregated SVNN matrix $D_{A g g}$ containing an aggregation of individual SVNN values. Using Table 3, experts assessed the various criteria linguistically, presented in Table 8. Usually, two types of criteria i.e., cost and benefit criteria are seen in MCDM

$$
\begin{aligned}
& D_{\text {Eucd }}^{i+}\left(d_{i j}^{W j}, d_{j}^{W+}\right)=\sqrt{\frac{1}{3 n} \sum_{j=1}^{n}\left\{\left(T_{i j}^{W j}\left(x_{j}\right)-T_{i j}^{W+}\left(x_{j}\right)\right)^{2}+\left(I_{i j}^{W j}\left(x_{j}\right)-I_{i j}^{W+}\left(x_{j}\right)\right)^{2}+\left(F_{i j}^{W j}\left(x_{j}\right)-F_{i j}^{W+}\left(x_{j}\right)\right)^{2}\right\}} \\
& D_{\text {Eucd }}^{i-}\left(d_{i j}^{W j}, d_{j}^{W-}\right)=\sqrt{\frac{1}{3 n} \sum_{j=1}^{n}\left\{\left(T_{i j}^{W j}\left(x_{j}\right)-T_{i j}^{W-}\left(x_{j}\right)\right)^{2}+\left(I_{i j}^{W j}\left(x_{j}\right)-I_{i j}^{W-}\left(x_{j}\right)\right)^{2}+\left(F_{i j}^{W j}\left(x_{j}\right)-F_{i j}^{W-}\left(x_{j}\right)\right)^{2}\right\}}
\end{aligned}
$$

8. Compute the relative closeness coefficient $C_{i}^{*}$ of every alternative concerning the RNPIS $\left(Q_{N}^{+}\right)$using Eq. (15). The value $C_{i}^{*}$ falls in the range of zero to one.

$$
C_{i}^{*}=\frac{D_{\text {Eucd }}^{i-}\left(d_{i j}^{W j}, d_{j}^{W-}\right)}{D_{\text {Eucd }}^{i+}\left(d_{i j}^{W j}, d_{j}^{W+}\right)+D_{\text {Eucd }}^{i-}\left(d_{i j}^{W j}, d_{j}^{W-}\right)}
$$

9. Arrange all the alternatives in descending according to $C_{i}^{*}$ The higher value of $C_{i}^{*}$ indicating a better alternative.

\section{Results and discussion}

Table 5 presents the list of 8 criteria for the evaluation of teaching modalities proposed on the basis of literature review and opinion of experts.

For the purpose of evaluating and prioritising teaching modalities same three experts were requested who helped in finalising common criteria for evaluation. Based on their skill, knowledge and experience, linguistic ratings were problems. The current study contains all benefit criteria for assessment, except DT (cost criteria). Criteria linguistic assessment is expressed into SVNN for producing criteria weight vector (W) by applying Eq. (3).

Multiplication of aggregated SVNN matrix is done with criteria weight vector $(\mathrm{W})$ to obtain $\mathrm{D}^{\mathrm{W}}$ i.e., $\mathrm{AWDM}$, as shown in Table 9.

Using Eqs. (5) and (6) $Q_{N}^{+}$and $Q_{N}^{-}$values are calculated. Then, Euclidean distance $\left(D_{\text {Eucd }}^{i+}\left(d_{i j}^{W j}, d_{j}^{W+}\right) a n d D_{\text {Eucd }}^{i-}\right.$ $\left.\left(d_{i j}^{W j}, d_{j}^{W-}\right)\right)$ a measure of every alternative from the $Q_{N}^{+}$and $Q_{N}^{-}$is calculated using Eqs. (13) and (14). Finally, the relative closeness coefficient is computed using Eq. (15). The ranking of teaching modalities based on descending order of closeness coefficient values are shown in Table 10. The higher the value closeness coefficient better is the alternative.

The assessment of teaching modalities is presented in the form of a ranking (refer to Table 8). The obtained ranking order is Flipped classroom teaching $>$ Blended teaching $>$ Face-to-face teaching $>$ Pure Online teaching. The flipped classroom teaching model found to best among 
Table 5 List of criteria for evaluating teaching modalities

\begin{tabular}{|c|c|c|c|}
\hline SNO & Criteria & Description & References \\
\hline 1 & $\begin{array}{l}\text { Learning Outcomes } \\
\text { (LO) }\end{array}$ & $\begin{array}{l}\text { These measurable statements describing learners' abilities after completing the } \\
\text { course successfully. They are also known as observable skills }\end{array}$ & $\begin{array}{l}\text { Woltering et al. (2009); Jesus } \\
\text { et al. (2017) }\end{array}$ \\
\hline 2 & $\begin{array}{l}\text { Level of Interaction } \\
\text { (LI) }\end{array}$ & $\begin{array}{l}\text { It can be described as meaningful communication among teachers and students } \\
\text { present in a class for conceptualising ideas and facts }\end{array}$ & $\begin{array}{l}\text { Appleton et al. (2008); Lee } \\
\text { (2020) }\end{array}$ \\
\hline 3 & $\begin{array}{l}\text { Student Engagement } \\
\text { (SE) }\end{array}$ & $\begin{array}{l}\text { These are enigmatic and multi-faceted meta-construct representing the extent to } \\
\text { which students' show attention, curiosity, interest, optimism, and passion in } \\
\text { the subject being taught }\end{array}$ & $\begin{array}{l}\text { Appleton et al. (2008); Chi } \\
\text { and Wylie (2014) }\end{array}$ \\
\hline 4 & $\begin{array}{l}\text { Student Assessment } \\
\text { (SA) }\end{array}$ & $\begin{array}{l}\text { It is the ongoing process of measuring students' knowledge, skill and abilities } \\
\text { during the teaching and learning process }\end{array}$ & $\begin{array}{l}\text { Murnane et al. (2005); Black } \\
\text { and Wiliam (2018) }\end{array}$ \\
\hline 5 & $\begin{array}{l}\text { Guidance, Support } \\
\text { and Feedback (GSF) }\end{array}$ & $\begin{array}{l}\text { The process adopted by instructors to assist learners in completing their } \\
\text { educational tasks, timely response given to them for their queries }\end{array}$ & $\begin{array}{l}\text { Hounsell et al. (2008); Van } \\
\text { den Bergh et al. (2014) }\end{array}$ \\
\hline 6 & Flexibility (FL) & $\begin{array}{l}\text { The teaching method allows the learner to manage their learning space. For } \\
\text { instance, how, what, when and where they want to learn }\end{array}$ & Vanslambrouck et al. (2018) \\
\hline 7 & $\begin{array}{l}\text { Course Management } \\
(\mathrm{CM})\end{array}$ & $\begin{array}{l}\text { The number of tasks done by teachers and institutions for classroom } \\
\text { management of various courses }\end{array}$ & Lane (2009) \\
\hline 8 & $\begin{array}{l}\text { Duration of Lecture } \\
\text { (DT) }\end{array}$ & The time devoted by a teacher for the presentation of the topic in the class & Lee $(2020)$ \\
\hline
\end{tabular}

Table 6 Linguistic assessment of experts

\begin{tabular}{lll}
\hline Experts & Linguistic Terms & SVNNs \\
\hline E1 & VI & $\langle 0.90,0.10,0.10\rangle$ \\
E2 & I & $\langle 0.80,0.20,0.15\rangle$ \\
E3 & M & $\langle 0.50,0.40,0.45\rangle$ \\
\hline
\end{tabular}

all teaching modalities. It is an accelerated learning approach. It combines out-class and in-class activities to foster attributes of metacognitive skills in the learner. Our finding flipped classroom teaching is better than other discussed teaching modalities is consistent with other studies (Cheng et al. 2019). Researchers posited that the
Table 8 Experts linguistic assessment of criteria

\begin{tabular}{lllllllll}
\hline Experts & LO & LI & SE & SA & GSF & FL & CM & DT \\
\hline E1 & I & MI & I & MI & I & I & M & MUI \\
E2 & M & I & I & MI & M & M & UI & M \\
E3 & I & M & I & I & I & M & UI & UI \\
\hline
\end{tabular}

flipped approach delivered positive results in many disciplines like medical studies, language learning, school, and higher education (Singh et al. 2018). The reason is online resources provides technical knowledge to students and e-assessment attempted by students ensures students' readiness for classroom deliberations. Here, students solve
Table 7 Assessment of teaching modalities by experts

\begin{tabular}{llllllllll}
\hline Teaching Modality & Experts & LO & LI & SE & SA & GSF & FL & CM & DT \\
\hline Face-to-face teaching & E1 & MS & N & N & VS & MS & ES & VS & VS \\
& E2 & MS & MI & IS & S & N & VS & S & S \\
& E3 & S & IS & MI & MS & MI & S & MS & MS \\
Pure online teaching & E1 & S & VS & MS & MS & S & MI & N & MI \\
& E2 & MS & S & MS & N & S & MI & MS & IS \\
& E3 & N & VS & N & MI & MS & MI & MS & VI \\
Blended teaching & E1 & ES & S & VS & S & VS & ES & S & S \\
& E2 & VS & MS & S & MS & S & VS & MS & S \\
& E3 & S & N & MS & N & MS & VS & N & MS \\
Flipped Classroom teaching & E1 & ES & VS & ES & ES & S & MS & MI & N \\
& E2 & VS & S & VS & ES & MS & N & IS & MI \\
& E3 & VS & MS & ES & ES & VS & MS & VI & IS \\
\hline
\end{tabular}


Table 9 Aggregated weighted decision matrix

\begin{tabular}{|c|c|c|c|c|c|c|c|c|}
\hline Teaching Modality & LO & LI & SE & SA & GSF & FL & $\mathrm{CM}$ & DT \\
\hline $\begin{array}{l}\text { Face-to-face } \\
\text { teaching }\end{array}$ & $\begin{array}{l}0.499,0.486 \\
0.422\end{array}$ & $\begin{array}{l}0.319,0.671 \\
0.637\end{array}$ & $\begin{array}{l}0.298,0.690 \\
0.651\end{array}$ & $\begin{array}{l}0.734,0.266 \\
0.167\end{array}$ & $\begin{array}{l}0.393,0.596 \\
0.537\end{array}$ & $\begin{array}{l}0.660,0.299 \\
0.284\end{array}$ & $\begin{array}{l}0.347,0.590 \\
0.628\end{array}$ & $\begin{array}{l}0.267,0.656 \\
0.702\end{array}$ \\
\hline $\begin{array}{l}\text { Pure online } \\
\text { teaching }\end{array}$ & $\begin{array}{l}0.506,0.479 \\
0.413\end{array}$ & $\begin{array}{l}0.712,0.280 \\
0.224\end{array}$ & $\begin{array}{l}0.497,0.503 \\
0.429\end{array}$ & $\begin{array}{l}0.480,0.520 \\
0.443\end{array}$ & $\begin{array}{l}0.559,0.425 \\
0.358\end{array}$ & $\begin{array}{l}0.231,0.509 \\
0.749\end{array}$ & $\begin{array}{l}0.248,0.707 \\
0.730\end{array}$ & $\begin{array}{l}0.079,0.887 \\
0.909\end{array}$ \\
\hline Blended teaching & $\begin{array}{l}0.723,0.256 \\
0.222\end{array}$ & $\begin{array}{l}0.572,0.422 \\
0.367\end{array}$ & $\begin{array}{l}0.664,0.336 \\
0.244\end{array}$ & $\begin{array}{l}0.619,0.381 \\
0.294\end{array}$ & $\begin{array}{l}0.600,0.382 \\
0.308\end{array}$ & $\begin{array}{l}0.660,0.299 \\
0.284\end{array}$ & $\begin{array}{l}0.293,0.654 \\
0.684\end{array}$ & $\begin{array}{l}0.249,0.680 \\
0.723\end{array}$ \\
\hline $\begin{array}{l}\text { Flipped Classroom } \\
\text { teaching }\end{array}$ & $\begin{array}{l}0.723,0.256 \\
0.222\end{array}$ & $\begin{array}{l}0.678,0.314 \\
0.254\end{array}$ & $\begin{array}{l}0.800,0.200 \\
0.150\end{array}$ & $\begin{array}{l}0.883,0.117 \\
0.064\end{array}$ & $\begin{array}{l}0.572,0.412 \\
0.339\end{array}$ & $\begin{array}{l}0.397,0.578 \\
0.532\end{array}$ & $\begin{array}{l}0.103,0.865 \\
0.886\end{array}$ & $\begin{array}{l}0.125,0.835 \\
\quad 0.855\end{array}$ \\
\hline
\end{tabular}

Table 10 Ranking of teaching Modalities

\begin{tabular}{lllll}
\hline Teaching Modalities & $D_{\text {Eucd }}^{i+}\left(d_{i j}^{W j}, d_{j}^{W+}\right)$ & $D_{\text {Eucd }}^{i-}\left(d_{i j}^{W j}, d_{j}^{W-}\right)$ & $C_{i}^{*}($ ClosenessCoefficient $)$ & Rank \\
\hline Face-to-face teaching & 0.271 & 0.192 & 0.414 & 3 \\
Pure online teaching & 0.251 & 0.176 & 0.412 & 4 \\
Blended teaching & 0.132 & 0.258 & 0.661 & 2 \\
Flipped Classroom teaching & 0.110 & 0.294 & 0.728 & 1 \\
\hline
\end{tabular}

non-trivial problems, attend brainstorming sessions that encourage collaborative learning among students, leading to capacity autonomous learning. Sun et al. (2018) highlighted that even instructors are advocating its usage. It can be said that it is a credible and better alternative in comparison to other discussed teaching modalities.

Blended learning occupied the second position in the ranking. It is found to be better than pure online and faceto-face teaching modalities. The finding concurs with the earlier work of Al-Qahtani and Higgins (2013). As discussed, it is often seen as an online extension of face-toface classroom teaching modality. Here instructions are delivered via synchronous and/or asynchronous chats or videoconference to supplement the conventional mode of teaching. Nevertheless, it promotes blended learning culture, combining positive pieces of training in the offline and online environment. Allen and Seaman (2013) noticed that in the blended form a substantial part of the course is covered online which typically ranges between 30 and $79 \%$ and the remaining course via face-to-face contact sessions. Precel et al. (2009) reported that there is no clear-cut formula for combining face-to-face teaching with a purely online approach. The major reason for getting lower rank than flipped classroom model, where in-class and out-class activities are clearly defined. Flipped classroom model deepens students learning by analysis, application of the area being studied through videos and problem-solving. On the other hand, in blended form, some of the activities carried out in class time are being replaced by online activities. Experts understand that flipped classroom approach fosters critical thinking and promotes active learning. It is more practical oriented. It improves academic outcomes by removing the gap between the strongest and weakest students.

Face to face teaching is at the third position. Generally, people believe that the physical presence of the instructor, proper brick and mortar classroom environment, the social environment of the classroom brings discipline in the life of students. Moreover, students do not feel isolated here leading to hedonic motivation. The classroom discussion gives students prompt responses and feedback. If the learner faces any difficulty, he/she may take the help of the instructor or fellow students. By solving the doubts instructor will also get an impression that students are trying to learn the things taught in the class. If the doubt is being solved by a fellow student, he or she feels more confident about the topic. Learners feel more comfortable in this traditional learning mode and prefer it. It is still prevalent in many countries as a primary teaching approach.

Pure online teaching got the last position i.e., fourth in the ranking of teaching modalities. The lowest ranking of online teaching may be attributed to the fact that the present study is conducted in developing country India where IT infrastructure is not very robust. Instructors and learners frequently face internet connectivity issue which makes teaching-learning less effective. In pure online teaching, personalised monitoring of students is difficult in comparison to face to face learning. The attention span in the pure online mode of teaching is very limited due to more one-way communication. Moreover, continuous online learning leads to health hazards like eyesight issues and 
body aches. Hence, experts feel that pure online teaching may take time to become more significant than face-to-face teaching.

\section{Contributions and suggestions}

The current study has many important contributions. First, it identified eight common criteria from the extant literature for comparing four teaching modalities. It was observed that most of the earlier studies compared teaching modalities with limited criteria such as student engagement, student performance, satisfaction and interaction. Second, after analysing linguistic term, it highlighted the relative significance of all the criteria in a particular mode. Third, as per the authors' knowledge, it is the first study that implemented SVNN extension of TOPSIS for prioritisation of teaching modalities. Fourth, the study compared four different types of teaching modalities.

This work presents a comprehensive picture of pedagogical approaches. The study showed that flipped classroom and blended teaching are the two best teaching approaches, in the category of technology-enabled learning. Literature suggested that both approaches are suitable for all types of learners irrespective of their age and gender. It is observed that some people lack computing skills. To popularise technology-based learning, firms developing apps of technology-based learning should utilise an intelligent tutoring system (ITS) to support learners in completing their tasks. Moreover, the study is conducted in India, which is a developing nation and densely populated. Demographics of the country reveal that the scope of technology-mediated learning is tremendous in India. Here, the majority of the population live in rural areas where the IT infrastructure is not very robust. Policymakers need to pay attention to these issues to achieve the objective of inclusive education. There is a requirement to invest more in IT infrastructure by government and private players. Internet service providing firms need to provide data packs to such people at a very nominal rate so that people falling in the lower-income group can easily afford it. There is a need for digital libraries and mobile libraries for the students having a lack of resources like mobile or data connection. These libraries can support such students in completing their studies through digital mode. In urban areas, educational institutes (school or colleges) are migrating towards pure online or blended mode of teaching. In reality, this migration is at its nascent stage. As the student body is growing and changing with time, it is the right time to change our teaching practices too. To encourage the acceptance of flipped classroom model and blended learning mode, educational institutes should give students group projects. The group should be formed in such a manner, students having desired resources for accessibility should be teamed with those having limited resources. In this manner, team spirits will be developed in the students. Nevertheless, the project should be based on software tools that are open source. Most importantly, pure virtual classroom teaching alone cannot serve the purpose of active learning. Active learning requires self-regulation behaviour in the students. Lacking such behaviour hinders technology-enabled learning from fulfilling its desired goals. To foster self-regulation behaviour, the effective intervention of teachers is required at regular time intervals. Moreover, by creating social identity grouping in a web environment self-regulation behaviour can easily be inculcated. Hence, the research suggests that teaching pedagogy must embrace technology for the benefit of learners as well as instructors.

\section{Conclusion}

The study aimed to evaluate and rank four different teaching modalities viz. offline conventional, virtual classroom, blended learning, and the flipped classroom. Three experts were consulted to assign linguistic terms to the aforementioned teaching modalities based on eight criteria chosen from the extant literature. Teaching modalities were prioritised using SVNN extension of TOPSIS. As per the authors' knowledge, it is the first-ever study that prioritised these teaching modalities using SVNN extension of TOPSIS. The flipped classroom was found to be the most effective teaching modality among all. The study suggested policymakers design policies that could support educational institutions in upgrading their technical infrastructure. The study also suggested how to boost the acceptance of technology-based learning in students by the timely and regular intervention of teachers.

\section{Limitations and future scope}

No study is without limitations. Likewise, the current study also has some limitations. The teaching approaches were evaluated and ranked based on opinion of 3 experts. Opinion of larger number of experts may be taken. Future studies may integrate techniques such as ANP and TOPSIS using interval-valued neutrosophic numbers to check the reliability of results. An exploratory study may also be conducted to determine more assessment criteria for teaching modalities.

Funding This research received no specific grant from any funding agency in the public, commercial, or not-for-profit sectors. 


\section{Declarations}

Conflict of interest The authors declare that they have no conflict of interest.

\section{References}

Allen IE, Seaman J (2013) Ten years of tracking online education in the United States. Babson Survey Research Group and Quahog Research Group

Al-Qahtani AA, Higgins SE (2013) Effects of traditional, blended and e-learning on students' achievement in higher education. J Comput Assist Learn 29(3):220-234

Appleton JJ, Christenson SL, Furlong MJ (2008) Student engagement with school: critical conceptual and methodological issues of the construct. Psychol Sch 45(5):369-386

Bailey M, Gosper M, Ifenthaler D, Ware C, Kretzschma M (2018) On-campus, distance or online? Influences on student decisionmaking about study modes at university. Aust J Educ Technol 34(5):72-85

Biswas P, Pramanik S, Giri BC (2019) Neutrosophic TOPSIS with group decision making. fuzzy multi-criteria decision-making using neutrosophic sets. Springer, Cham, pp 543-585

Black P, Wiliam D (2018) Classroom assessment and pedagogy. Assess Educ Princ Pol Pract 25:1-25

Boran FE, Genç S, Kurt M, Akay D (2009) A multi-criteria intuitionistic fuzzy group decision making for supplier selection with TOPSIS method. Expert Syst Appl 36(8):11363-11368

Broadbent J (2017) Comparing online and blended learner's selfregulated learning strategies and academic performance. The Internet Higher Educ 33:24-32

Browne E (2005) Structural and pedagogic change in further and higher education: a case study approach. J Furth High Educ 29(1):49-59

Buddhapriya S, Bhatt P (2018) Intrinsic motivational potential inventory: development of a measure. Int $\mathrm{J}$ Indian Cult Bus Manag 17(4):478-501

Cazden CB (1988) Classroom discourse: the language of teaching and learning

Chen CT (2000) Extensions of the TOPSIS for group decisionmaking under fuzzy environment. Fuzzy Sets Syst 114(1):1-9

Cheng L, Ritzhaupt AD, Antonenko P (2019) Effects of the flipped classroom instructional strategy on students' learning outcomes: a meta-analysis. Educ Tech Res Dev 67(4):793-824

Chi MT, Wylie R (2014) The ICAP framework: linking cognitive engagement to active learning outcomes. Educ Psychol 49(4):219-243

Chu SK, Mok SS (2016) Changing organizational structure and culture to enhance teaching and learning: Cases in a university in Hong Kong. Organizing academic work in higher education: teaching, learning and identities, 186-202

Cohen J (1960) A coefficient of agreement for nominal scales. Educ Psychol Measur 20(1):37-46

Das R, Smarandache F, Tripathy BC (2020) Neutrosophic fuzzy matrices and some algebraic operations. Infinite Study

Dhawan S (2020) Online learning: a panacea in the time of COVID19 crisis. J Educ Technol Syst 49(1):5-22

Gopalan S, Cherikh M, Balakrishnan L (2018) An exploratory investigation of motivation orientations of Indian business students: implications for educators. Int $\mathrm{J}$ Indian Cult Bus Manag 17(4):455-477

Grimes EB (2002) Student perceptions of an online dental terminology course. J Dent Educ 66(1):100-107

Hounsell D, McCune V, Hounsell J, Litjens J (2008) The quality of guidance and feedback to students. High Educ Res Dev 27(1):55-67
Hsu LL, Hsieh SI (2011) Effects of a blended learning module on self-reported learning performances in baccalaureate nursing students. J Adv Nurs 67(11):2435-2444

Huang R, Tlili A, Wang H, Shi Y, Bonk CJ, Yang J, Burgos D (2021) Emergence of the online-merge-offline (OMO) learning wave in the post-COVID-19 era: a pilot study. Sustainability 13(6):3512

Hwang CL, Yoon K (1981) Methods for multiple attribute decision making. In: Multiple attribute decision making. Springer, Berlin, Heidelberg, pp 58-191

Johnson L, Becker SA, Cummins M, Estrada V, Freeman A, Hall C (2016) NMC horizon report: 2016 higher education edition (pp. 1-50). The New Media Consortium

Jesus A, Gomes MJ, Cruz A (2017) Blended versus face-to-face: comparing student performance in a therapeutics class. The Inst Eng Technol 11(3):135-140

Kalpokaite N, Radivojevic I (2020) Teaching qualitative data analysis software online: a comparison of face-to-face and e-learning ATLAS ti courses. Int J Res Method Educ 43(3):296-310

Kitchenham B, Brereton OP, Budgen D, Turner M, Bailey J, Linkman S (2009) Systematic literature reviews in software engineering-a systematic literature review. Inf Softw Technol 51(1):7-15

Lane LM (2009) Insidious pedagogy: how course management systems affect teaching. First Monday

Landis JR, Koch GG (1977) The measurement of observer agreement for categorical data. Biometrics 159-174

Lee SH (2020) Factors affecting satisfaction with online lectures for real-time learning. J Korean Soc Dental Hyg 20(5):561-569

Lewis R (1993) The progress of open learning. Education+ Training

Li Z, Shan D (2020) Analysis of teaching cases from offline to online mode. Teach Educ Curric Stud 5(4):156

Li X, Yang Y, Chu SKW, Zainuddin Z, Zhang Y (2020) Applying blended synchronous teaching and learning for flexible learning in higher education: an action research study at a university in Hong Kong. Asia Pac J Educ 1-17

Liberati A, Altman DG, Tetzlaff J, Mulrow C, Gøtzsche PC, Ioannidis JP, Moher D (2009) The PRISMA statement for reporting systematic reviews and meta-analyses of studies that evaluate health care interventions: explanation and elaboration. J Clin Epidemiol 62(10):e1-e34

Mahmood S (2021) Instructional strategies for online teaching in COVID-19 pandemic. Human Behav Emerg Technol 3(1):199-203

McKenna K, Gupta K, Kaiser L, Lopes T, Zarestky J (2020) Blended learning: balancing the best of both worlds for adult learners. Adult Learn 31(4):139-149

Means B, Toyama Y, Murphy R, Baki M (2013) The effectiveness of online and blended learning: a meta-analysis of the empirical literature. Teach Coll Rec 115(3):1-47

Ministry of Rural Development (2020) Poverty measurement in India: a status update

Moazami F, Bahrampour E, Azar MR, Jahedi F, Moattari M (2014) Comparing two methods of education (virtual versus traditional) on learning of Iranian dental students: a post-test only design study. BMC Med Educ 14(1):1-5

Moayeri M, Shahvarani A, Behzadi MH, Hosseinzadeh-Lotfi F (2015) Comparison of fuzzy AHP and fuzzy TOPSIS methods for math teachers selection. Indian J Sci Technol 8(13):1

Moher D, Liberati A, Tetzlaff J, Altman DG (2009) Preferred reporting items for systematic reviews and meta-analyses: the PRISMA statement. Ann Intern Med 151(4):264-269

Murnane RJ, Sharkey NS, Boudett KP (2005) Using studentassessment results to improve instruction: Lessons from a workshop. J Educ Stud Placed Risk 10(3):269-280

Murphy CA, Stewart JC (2017) On-campus students taking online courses: factors associated with unsuccessful course completion. The Internet High Educ 34:1-9 
Namaziandost E, Çakmak F (2020) An account of EFL learners' selfefficacy and gender in the Flipped Classroom Model. Educ Inform Technol 1-15

Nguyen T (2015) The effectiveness of online learning: beyond no significant difference and future horizons. Merlot J Online Learn Teach 11(2):309-319

Nguyen-Duc A, Cruzes DS, Conradi R (2015) The impact of global dispersion on coordination, team performance and software quality-a systematic literature review. Inf Softw Technol 57:277-294

Onah DF, Pang EL, Sinclair JE (2020) Cognitive optimism of distinctive initiatives to foster self-directed and self-regulated learning skills: a comparative analysis of conventional and blended-learning in undergraduate studies. Educ Inf Technol 25(5):4365-4380

Pei L, Wu H (2019) Does online learning work better than offline learning in undergraduate medical education? A systematic review and meta-analysis. Med Educ Online 24(1):1666538

Petersen K, Feldt R, Mujtaba S, Mattsson M (2008) Systematic mapping studies in software engineering. In: 12th international conference on evaluation and assessment in software engineering (EASE) 12, 1-10

Pramanik SURAPATI, Dalapati SHYAMAL, Roy TK (2016) Logistics center location selection approach based on neutrosophic multi-criteria decision making. New Trends in Neutrosophic Theories and Applications, Pons-Editions, Brussels, 161-174

Pramanik S, Mondal K (2015) Cotangent similarity measure of rough neutrosophic sets and its application to medical diagnosis. J New Theory 4:90-102

Precel K, Eshet-Alkalai Y, Alberton Y (2009) Pedagogical and design aspects of a blended learning course. International Review of Research in Open and Distributed Learning 10(2)

Redmond P (2011) From face-to-face teaching to online teaching: Pedagogical transitions. In Proceedings ASCILITE 2011: 28th annual conference of the Australasian Society for Computers in Learning in Tertiary Education: Changing demands, changing directions (pp. 1050-1060). Australasian Society for Computers in Learning in Tertiary Education (ASCILITE)

Roach V, Lemasters L (2006) Satisfaction with online learning: a comparative descriptive study. J Interact Online Learn 5(3):317-332

Ryan MD, Reid SA (2015) Impact of the flipped classroom on student performance and retention: a parallel controlled study in general chemistry. J Chem Educ 93(1):13-23

Sahin A, Cavlazoglu B, Zeytuncu YE (2015) Flipping a college calculus course: a case study. J Educ Technol Soc 18(3):142-152

Smallhorn M (2017) The flipped classroom: a learning model to increase student engagement not academic achievement. Stud Success 8(2):43-53

Smarandache F (1999) A unifying field in Logics: neutrosophic Logic. In Philosophy (pp. 1-141). American Research Press

Smarandache F (1998) Neutrosophy: neutrosophic probability, set, and logic: analytic synthesis \& synthetic analysis

Singh K, Mahajan R, Gupta P, Singh T (2018) Flipped classroom: a concept for engaging medical students in learning. Indian Pediatr 55(6):507-512

Smets P (1999) Imperfect information: imprecision-uncertainty en uncertainty management in information systems: from needs to solutions. Kluwer Academics Publisher, Amuhai Motro and Phillip Smets

Strelan P, Osborn A, Palmer E (2020) The flipped classroom: a metaanalysis of effects on student performance across disciplines and education levels. Educ Res Rev 30:100314

Sujatha R, Krishnaveni R (2020) Knowledge management practices as an antecedent for enabling work performance of employees: empirical evidence from pump and motor manufacturing cluster in India. Int J Indian Cult Bus Manag 20(3):289-306
Sun Z, Xie K, Anderman L (2018) The role of self-regulated learning in students' success in flipped undergraduate math courses. The Internet Higher Educ 36:41-53

Tomas L, Doyle T, Skamp K (2019) Are first year students ready for a flipped classroom? A case for a flipped learning continuum. Int J Education Tech High Educ 16(1):1-22

Tan RP, Wen-de Z (2021) Decision-making method based on new entropy and refined single-valued neutrosophic sets and its application in typhoon disaster assessment. Appl Intell 51(1):283-307

Tang F, Chen C, Zhu Y, Zuo C, Zhong Y, Wang N, Liang D (2017) Comparison between flipped classroom and lecture-based classroom in ophthalmology clerkship. Med Educ Online 22(1):1395679

Ubell R (2017) Why faculty still don't want to teach online. Online Research Consortium Blog. Retrieved from https://onlinelear ningconsortium.org/faculty-still-dont-want-teach-online/

van Alten DC, Phielix C, Janssen J, Kester L (2019) Effects of flipping the classroom on learning outcomes and satisfaction: a meta-analysis. Educ Res Rev 28:100281

Van den Bergh L, Ros A, Beijaard D (2014) Improving teacher feedback during active learning: effects of a professional development program. Am Educ Res J 51(4):772-809

Vanslambrouck S, Zhu C, Lombaerts K, Philipsen B, Tondeur J (2018) Students' motivation and subjective task value of participating in online and blended learning environment. The Internet Higher Educ 36:33-40

Wang H, Smarandache F, Zhang Y, Sunderraman R (2010) Single valued neutrosophic sets. Infinite study

Wei X, Cheng IL, Chen NS, Yang X, Liu Y, Dong Y, Zhai X (2020) Effect of the flipped classroom on the mathematics performance of middle school students. Educ Technol Res Dev 1-24

Westbury I (1973) Conventional classrooms, "open" classrooms and the technology of teaching. J Curric Stud 5(2):99-121

Wheeler JV, Carr AS, Cady SH, Schumacher L (2020) Selfmanagement and work performance: an exploratory crosscultural study. Int J Indian Cult Bus Manag 20(4):510-533

Wright BM (2017) Blended learning: Student perception of face-to-face and online EFL lessons. Indonesian J Appl Linguist 7(1):64-71

Wilson SG (2013) The flipped class: a method to address the challenges of an undergraduate statistics course. Teach Psychol 40(3):193-199

Woltering V, Herrler A, Spitzer K, Spreckelsen C (2009) Blended learning positively affects students' satisfaction and the role of the tutor in the problem-based learning process: results of a mixed-method evaluation. Adv Health Sci Educ 14(5):725

Ye J (2014) A multicriteria decision-making method using aggregation operators for simplified neutrosophic sets. J Intell Fuzzy Syst 26(5):2459-2466

Yen SC, Lo Y, Lee A, Enriquez J (2018) Learning online, offline, and in-between: comparing student academic outcomes and course satisfaction in face-to-face, online, and blended teaching modalities. Educ Inf Technol 23(5):2141-2153

Yoon KP, Hwang CL (1995) Multiple attribute decision making: an introduction. Sage publications, USA

Zhou C (2020) Lessons from the unexpected adoption of online teaching for an undergraduate genetics course with lab classes. Biochem Mol Biol Educ 48(5):460-463

Zhü K (2014) Fuzzy analytic hierarchy process: fallacy of the popular methods. Eur J Oper Res 236(1):209-217

Publisher's Note Springer Nature remains neutral with regard to jurisdictional claims in published maps and institutional affiliations. 